\title{
Effect of salmeterol/fluticasone propionate on airway inflammation in COPD: a randomised controlled trial
}

\author{
Jean Bourbeau, Pota Christodoulopoulos, Francois Maltais, Yasuhiro Yamauchi, Ronald Olivenstein, \\ Qutayba Hamid
}

Thorax 2007;62:938-943. doi: 10.1136/thx.2006.071068

See end of article for authors' affiliations

Correspondence to:

Professor Qutayba Hamid,

Meakins Christie

Laboratories, McGill

University, 3626 St Urbain

Street, Montreal, Quebec,

Canada H2X 2P2; qutayba.

hamid@mcgill.ca

Received 31 August 2006

Accepted 5 April 2007

Published Online First

8 June 2007
Background: Airway inflammation in chronic obstructive pulmonary disease (COPD) is characterised by infiltration of CD8+ T cells and CD68+ macrophages and an increased number of neutrophils, whereas few studies have described the presence of eosinophils. Although the anti-inflammatory effects of corticosteroids in stable COPD are unclear, recent studies suggest that combination therapy could be beneficial. A study was therefore undertaken to evaluate combined salmeterol/fluticasone propionate (SFC) and fluticasone propionate (FP) alone on inflammatory cells in the airways of patients with COPD.

Methods: Patients were treated in a randomised, double blind, parallel group, placebo-controlled trial with either a combination of $50 \mu \mathrm{g}$ salmeterol and $500 \mu \mathrm{g}$ FP twice daily (SFC, $\mathrm{n}=19,19$ men, mean age 62 years), $500 \mu \mathrm{g}$ FP twice daily ( $\mathrm{n}=20,15$ men, mean age 64 years) or placebo ( $\mathrm{n}=21,17$ men, mean age 66 years) for 3 months. At the start and end of treatment bronchoscopy with bronchial biopsies was performed and the numbers of CD8+ Tlymphocytes, CD68+ macrophages, neutrophils and eosinophils were measured.

Results: CD8+ cells were significantly reduced by SFC compared with placebo (difference -98.05 cells/ $\mathrm{mm}^{2} ; 95 \% \mathrm{Cl}-143.14$ to $\left.-52.9 ; \mathrm{p}<0.001\right)$. Such a marked effect was not seen with FP alone $\left(-44.67\right.$ cells $/ \mathrm{mm}^{2} ; 95 \% \mathrm{Cl}-90.92$ to $\left.1.57 ; p=0.06\right)$. CD68+ macrophages were also reduced by SFC compared with placebo (difference -31.68 cells $/ \mathrm{mm}^{2} ; 95 \% \mathrm{Cl}-61.07$ to $-2.29 ; \mathrm{p}=0.03$ ) but not by FP. SFC did not significantly change neutrophils and eosinophils compared with placebo.

Conclusions: SFC has airway anti-inflammatory effects not seen with inhaled corticosteroids alone.
C hronic obstructive pulmonary disease (COPD) is a multicomponent disease characterised by progressive airflow limitation that is not fully reversible. Central to its pathogenesis is a chronic inflammatory process throughout the airways, parenchyma and pulmonary vasculature resulting in many structural changes.

The predominant pattern of airway inflammation in COPD is a prevalence of $\mathrm{T}$ lymphocytes and macrophages which have been shown to correlate with disease severity. T lymphocytes, with a greater increase in CD8+ than in CD4+ T cells, have been shown to relate to lung destruction and inversely to decline in lung function. ${ }^{2-4}$ CD68+ macrophages appear to play a pivotal role in COPD. ${ }^{5-7}$ A correlation has been demonstrated between macrophages in the airways and parenchymal destruction, chronic exposure to cigarette smoke and COPD severity. ${ }^{23}{ }^{7-9}$ Neutrophils are also increased within COPD airways, ${ }^{10} 11$ although their role is not completely understood. They have been associated with COPD disease severity and with the rate of decline in lung function, ${ }^{512}$ as they have the capacity to induce tissue damage through the release of various oxidants and proteases. Increased numbers of eosinophils have also been reported but their role in COPD remains questionable. ${ }^{13}$

Although there is evidence that inhaled corticosteroids reduce COPD exacerbations, ${ }^{14}$ their beneficial effects on airway inflammation in stable COPD appear limited. ${ }^{15}{ }^{16}$ However, a combination of long-acting $\beta_{2}$ agonist and inhaled corticosteroid not only reduces exacerbations in COPD but improves lung function and symptom control ${ }^{17-19}$ to a greater extent than either component alone. Recently, combination therapy has been shown to reduce airway inflammation in COPD. ${ }^{20}$

To date, however, there has been no comprehensive study examining differences in the effects of combination therapy and inhaled corticosteroids alone on the inflammatory profile in COPD airways. We postulated that a combination of a longacting $\beta_{2}$ agonist with an inhaled corticosteroid-and, to a lesser extent, inhaled corticosteroid alone-would reduce airway inflammation, specifically CD8+ $\mathrm{T}$ cells and CD68+ macrophages in COPD after 3 months of treatment. Furthermore, as a secondary outcome in this study, we set out to investigate the treatment effect on neutrophils and eosinophils and the relationship of anti-inflammatory effects to clinical outcomes (lung function as assessed by forced expiratory volume in $1 \mathrm{~s}\left(\mathrm{FEV}_{1}\right)$ and health-related quality of life as assessed by the Chronic Respiratory Questionnaire (CRQ)) in patients with COPD.

\section{METHODS}

\section{Patient population}

Sixty subjects with a clinical diagnosis of $\mathrm{COPD}^{21}$ were recruited between September 2002 and April 2005 from two respiratory centres, the Montreal Chest Institute and Hôpital Laval, Canada. Subjects were eligible for this study if they met the following criteria: age $\geqslant 40$ and $\leqslant 75$ years; smoking history ( $\geqslant 10$ pack-years); post-bronchodilator $\mathrm{FEV}_{1} \geqslant 25 \%$ of predicted value and $\mathrm{FEV}_{1} /$ forced vital capacity $(\mathrm{FVC}) \leqslant 0.70$; no history of asthma, atopy (as assessed by an allergy skin prick test during screening) or any other active lung disease. Patients on home oxygen or with raised carbon dioxide tension $(>44 \mathrm{~mm} \mathrm{Hg}$ ),

\footnotetext{
Abbreviations: $B A L$, bronchoalveolar lavage; COPD, chronic obstructive pulmonary disease; CRQ, Chronic Respiratory Questionnaire; $\mathrm{FEV}_{1}$, forced expiratory volume in $1 \mathrm{~s}$; FP, fluticasone propionate; FVC, forced vital capacity; SFC, salmeterol xinafoate/fluticasone propionate; TLCO, carbon monoxide transfer factor
} 
$\alpha_{1}$-antitrypsin deficiency, recent exacerbation (in the last 4 weeks), uncontrolled medical condition or hypersensitivity to inhaled corticosteroids and bronchodilators were not eligible for the study. Short-acting bronchodilators, short and longacting anticholinergics or theophylline were allowed throughout the study. Oral corticosteroids and/or antibiotics could only be given in short courses for exacerbation treatment. The study was approved by the research ethics committees at the participating centres and all patients gave written informed consent to participate.

\section{Study design}

This study was designed as a double blind, randomised, placebo controlled, parallel group clinical trial with subjects allocated to receive treatment with salmeterol xinafoate/fluticasone propionate (SFC; Advair/Seretide/Viani, GlaxoSmithKline) Diskus (50/500 $\mu \mathrm{g}$ twice daily), fluticasone propionate (FP; Flovent/ Flixotide, GlaxoSmithKline) Diskus (500 $\mu \mathrm{g}$ twice daily) or matched placebo Diskus twice daily. Randomisation was performed using a central computer generated list of random numbers which was stratified by centre and which used a block size of six set up by a data management/randomisation company (GEREQ, Montreal, Quebec). A procedure was established by GEREQ, who were in possession of the treatment code, to ensure that the treatment code would be broken only in accordance with the protocol and the criteria set up for unblinding the study (eg, due to a serious adverse event possibly related to the study treatment).

The total study duration was 16 weeks. After a 4-week washout period from inhaled corticosteroids and long-acting $\beta_{2}$ agonists, subjects were randomised to one of the treatment groups for 12 weeks. Bronchial biopsies were obtained at visit 2 (before treatment initiation) and after 12 weeks of treatment at visit 4 at the end of study. Pre- and post-bronchodilator spirometric measurements ( $\mathrm{FEV}_{1}$ and $\mathrm{FVC}$ ) and administration of the $\mathrm{CRQ}^{22}$ were performed at visit 2 and after 4 and 12 weeks of treatment. The ATS-DLD 78 questionnaire ${ }^{23}$ was administered at visit 2 and measurements of lung volumes and carbon monoxide transfer factor (TLCO) were made. Bronchoalveolar lavage (BAL) fluid was collected following the bronchoscopy procedure and sputum induction was performed on three occasions (2-4 days before bronchoscopy at randomisation, after 4 weeks of treatment and at the end of treatment); analysis of these samples has not yet been completed and will be the subject of a future publication.

\section{Tissue preparation}

With the use of an Olympus BF fibreoptic bronchoscope, endobronchial biopsy specimens were obtained according to American Thoracic Society guidelines. ${ }^{24}$ Six specimens from the subsegmental bronchus were obtained from the right lower, middle and upper lung using cup forceps. In preparation for immunocytochemistry, the bronchial biopsies were fixed accordingly and processed as either frozen sections or paraffin embedded sections as previously described..$^{25}$

\section{Immunocytochemistry}

In order to phenotype the inflammatory cells present in the biopsy samples, monoclonal antibodies directed against markers for T lymphocytes (CD8; Vector 4B11), macrophages (CD68; DAKO Diagnostics KP11), eosinophils (MBP; DAKO BMK13) and neutrophils (elastase; DAKO NP57) were used. CD8+ and CD68+ cells were stained on paraffin sections whereas frozen sections were used to detect eosinophils and neutrophils, since these two cell types are not easily detected on paraffin embedded sections. ${ }^{27}$ Immunocytochemistry was performed using a modified alkaline phosphatase antialkaline phosphatase method as previously described. ${ }^{28}$ Briefly, frozen sections were thawed, blocked in Universal Blocking Solution (DAKO Diagnostics) for $15 \mathrm{~min}$ and incubated with optimum concentration of the primary antibody overnight at $4^{\circ} \mathrm{C}$ in a humidified chamber. The next day the slides were washed in Tris-buffered saline solution ( $\mathrm{pH} 7.2)$, incubated with secondary antibody, and finally incubated with mouse alkaline phosphatase antialkaline phosphatase (DAKO). The reactions were then visualised by adding alkaline phosphatase substrate to the Fast Red (Sigma Chemical Company). Paraffin embedded tissue sections were stained using the strepavidin biotin peroxidase procedure. ${ }^{29}$ Briefly, tissue sections were deparaffinised, dehydrated and blocked in 3\% hydrogen peroxide for $5 \mathrm{~min}$. Antigen retrieval was enhanced by placing sections in a heat-induced epitope retrieval solution (EDTA buffer pH 8.0 for CD8 detection; Tris buffer pH 10 for CD68). Primary antibody was then applied for $\mathrm{l} \mathrm{h}$ at room temperature. A goat anti-rabbit secondary antibody conjugated to horseradish peroxidase (DAKO K377) was then applied. A coloured reaction was achieved by treating the slides with 3,3 diaminobenzidine (Sigma D5637). For negative controls the primary antibody was replaced by an isotype-matched control antibody.

Not all samples were stained at once but were done in batches; however, we made sure that pre and post biopsies from each individual subject were stained in the same run. Similarly, cell counting was delayed until there were sufficient pre and post biopsies to be randomised. The number of positive cells was averaged from six to eight random non-overlapping fields from two biopsy samples per subject and expressed as the mean number of positive cells per $\mathrm{mm}^{2}$. Cell counts were performed blind by two independent observers using an Olympus light microscope (Carson Group, Markam, Ontario, Canada) with $<400 \times$ magnification with an eyepiece graticule of $0.202 \mathrm{~mm}^{2}$. Observers were blinded not only to drug treatment but also to whether the biopsies were pre or post treatment. The level of agreement between blinded counters was $>90 \%$. The results of cell counts from the two counters were averaged.

\section{Statistical methods}

All data management and data analyses were performed by the authors. The main outcome variables in this study were the treatment difference in the numbers of CD8+ T lymphocytes and CD68+ macrophages in bronchial biopsies. Each end point has been analysed as a change from baseline. The primary treatment comparisons were between SFC and placebo, and FP and placebo, and secondary treatment comparisons were between SFC and FP. The secondary outcome variables were the number of neutrophils and eosinophils in bronchial biopsies. Since, at the time of starting this trial, no previous study using a combination of inhaled corticosteroid and longacting $\beta_{2}$ agonist had assessed the airway inflammatory response in COPD, the sample size was difficult to quantify. Based on a previous study ${ }^{16}$ and similar studies in asthma, we estimated the number of patients to be 20 per treatment group for the primary comparisons. Confidence intervals were provided to estimate the size of any treatment effects and these were used to determine the clinical relevance of the results. Statistical analysis was performed using data processed by $\mathrm{R}$, a language and environment for statistical computing ( $\mathrm{R}$ Foundation for Statistical Computing; Vienna, Austria). All available on-treatment data were included in the summary and analyses. As expected, some of the data were not normally distributed, but the difference between the results posttreatment minus pretreatment passed the test for normality in all cases. As such, data were analysed by Anova tests with Tukey honest significant comparisons a posteriori. Since the 


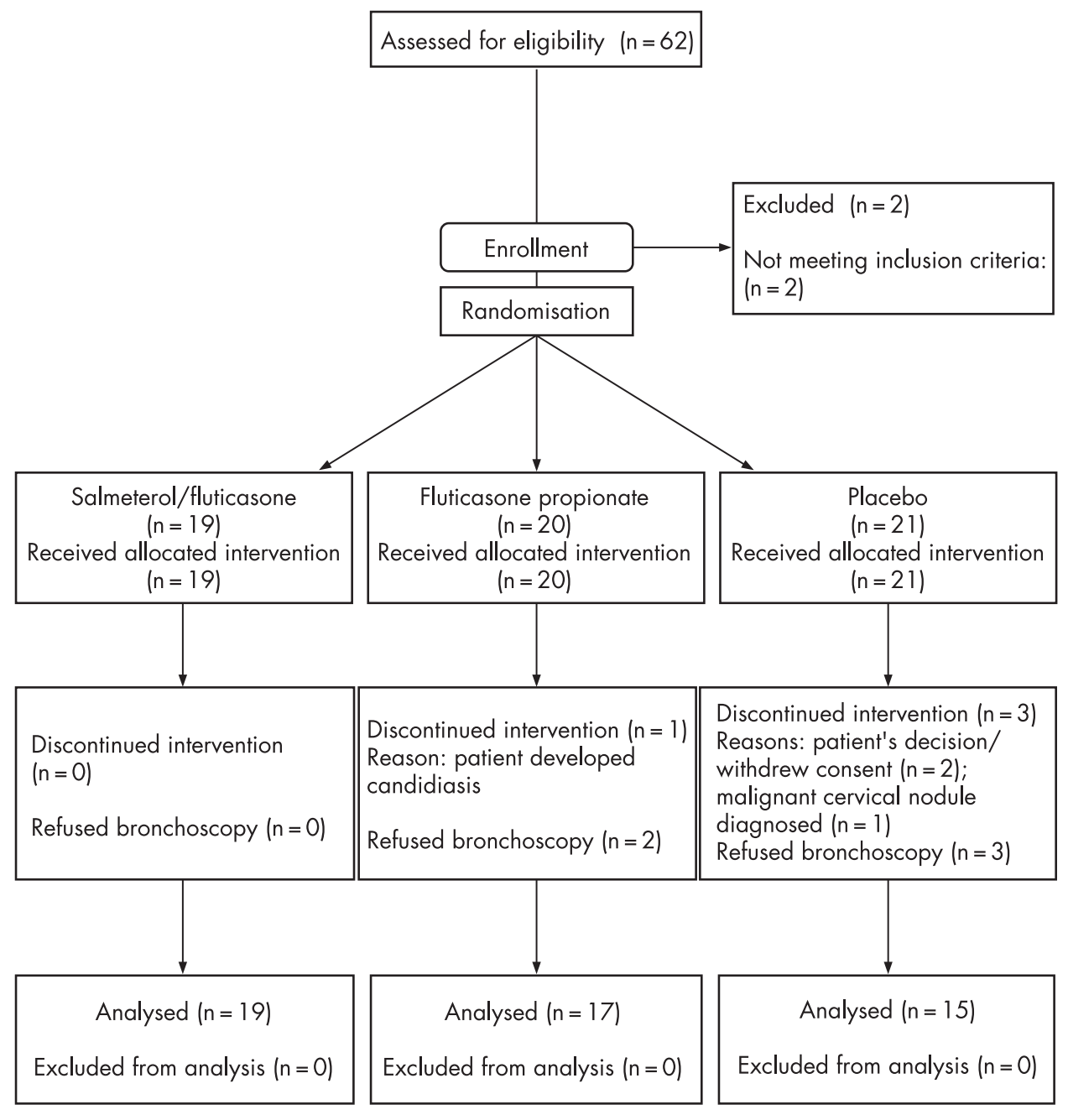

Figure 1 Flowchart of patient disposition through the study.

main outcome was limited to CD8+ T lymphocytes and CD68+ macrophages in bronchial biopsies and the different end points in this study were considered to represent separate pathways, they were treated independently and no adjustments for multiplicity were performed.

\section{RESULTS}

Sixty eligible subjects were randomised to treatment, 19 to the SFC treatment arm, 20 to the FP arm and 21 to the placebo arm (fig 1). Five subjects refused to have bronchoscopy performed and four subjects did not provide a post-treatment biopsy

Table 1 Baseline characteristics of study patients

\begin{tabular}{|c|c|c|c|}
\hline & $\begin{array}{l}\text { SFC } \\
(n=19)\end{array}$ & $\begin{array}{l}\text { FP } \\
(n=20)\end{array}$ & $\begin{array}{l}\text { Placebo } \\
(n=21)\end{array}$ \\
\hline Mean (SD) age (years) & $62(9)$ & $64(8)$ & $66(8)$ \\
\hline Male/female (n) & $19 / 0$ & $15 / 5$ & $17 / 4$ \\
\hline Current/former smokers ( $\mathrm{n}$ ) & $10 / 9$ & $10 / 10$ & $8 / 13$ \\
\hline Mean (SD) pack-years & $65(33)$ & $54(24)$ & $52(20)$ \\
\hline Mean (SD) post-BD FEV 1 (\% predicted) & $61(24)$ & 57 (19) & 57 (19) \\
\hline Mean (SD) BD reversibility $(\%)^{*}$ & $9(10)$ & $8(9)$ & $14(15)$ \\
\hline Mean (SD) TLCO (\%) & $68(15)$ & $67(17)$ & $67(17)$ \\
\hline \multicolumn{4}{|l|}{ GOLD stages $(n)$} \\
\hline I: $\mathrm{FEV}_{1} \geqslant 80 \%$ & 4 & 3 & 3 \\
\hline II: $50 \% \leqslant \mathrm{FEV}_{1}<80 \%$ & 6 & 10 & 9 \\
\hline III-IV: FEV $1 \leqslant 50 \%$ & 9 & 7 & 9 \\
\hline \multicolumn{4}{|l|}{ Respiratory medications before study (n) } \\
\hline Short-acting bronchodilators & 12 & 13 & 13 \\
\hline Long-acting anticholinergic agent & 3 & 3 & 3 \\
\hline Long-acting $\beta_{2}$ agonists & 1 & 1 & 3 \\
\hline Inhaled corticosteroids & 1 & 1 & 3 \\
\hline Long-acting $\beta_{2}$ agonists/inhaled corticosteroids & 3 & 6 & 5 \\
\hline Theophylline & 1 & 0 & 0 \\
\hline
\end{tabular}

SFC, salmeterol xinafoate/fluticasone propionate; FP, fluticasone propionate; BD, bronchodilator; FEV 1 , forced expiratory volume in $1 \mathrm{~s}$; TLCO, carbon monoxide transfer factor.

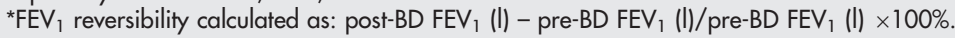



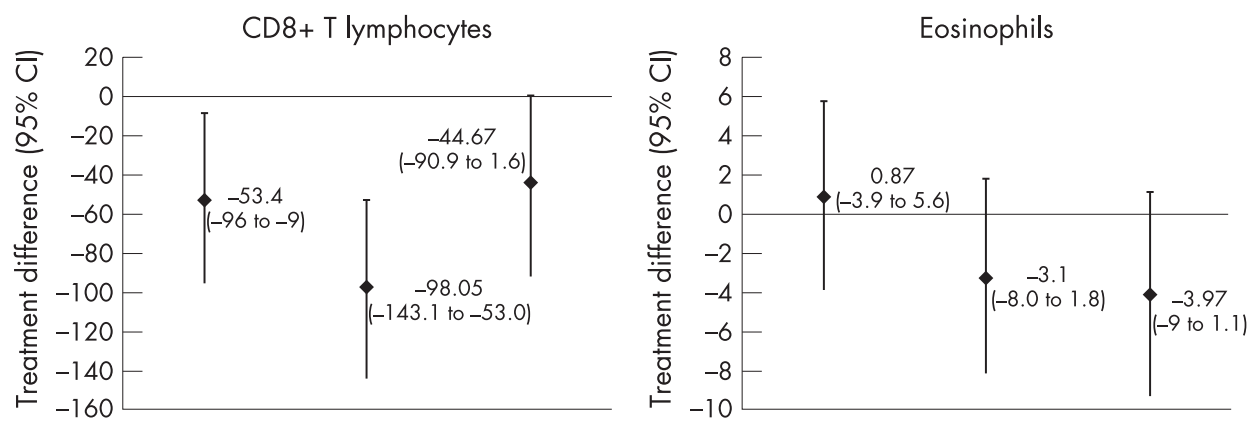

Figure 2 Treatment differences for CD8 T lymphocytes, CD68 macrophages, eosinophils and neutrophils. Data expressed as mean difference in the number of cells and $95 \%$ confidence interval. SFC, salmeterol xinafoate/fluticasone propionate; FP, fluticasone propionate; $P$, placebo.

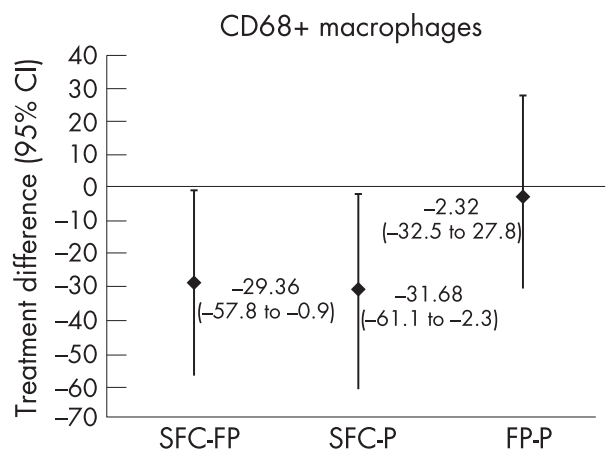

because they withdrew prematurely. Biopsy data before and after treatment were therefore available for analysis from 51 subjects ( 19 treated with SFC, 17 treated with FP and 15 treated with placebo). One patient in the placebo group received treatment for only 2 months.

The demographic characteristics, smoking history, baseline lung function, respiratory symptoms and prior respiratory medications of the randomised patients are summarised in table 1. Patients were primarily male, half of the patients were current smokers, and most of them (83\%) had a disease severity of GOLD (Global initiative for Obstructive Lung Disease) stages II-IV. ${ }^{21}$

\section{Primary end point}

Following 12 weeks of treatment, a statistically significant fall from baseline in the numbers of CD8+ $\mathrm{T}$ lymphocytes $(p<0.001)$ and CD68+ macrophages $(p=0.008)$ was seen after treatment with SFC but not with FP alone (table 2). As shown in fig 2, the mean differences in the number of $\mathrm{CD} 8+\mathrm{T}$ lymphocytes and CD68+ macrophages between SFC and placebo were statistically significant $(\mathrm{p}<0.001$ and $\mathrm{p}=0.03$, respectively). The mean differences in CD8+ T lymphocytes and CD68+ macrophages between FP and placebo failed to reach statistical significance. The mean differences in $\mathrm{CD} 8+\mathrm{T}$ lymphocytes and CD68+ macrophages between SFC and FP were statistically significant $(p=0.01$ and $p=0.04$ for CD8+ cells and CD68+ cells, respectively).

\section{Secondary end points}

Neither treatment had significant effects on the low numbers of biopsy neutrophils and eosinophils, although there was an increase from baseline in neutrophil numbers with FP that approached statistical significance $(p=0.07$, table 2$)$. Although there was no significant difference in the number of neutrophils between SFC and placebo, the number of neutrophils was significantly lower for SFC than for FP alone $(\mathrm{p}<0.001$, fig 2$)$. Furthermore, the comparison between FP and placebo showed a lower number of neutrophils in the placebo arm $(p=0.005)$. No statistically significant differences were seen between treatments for the number of eosinophils.

\section{Clinical outcomes}

No evidence of improvement in clinical outcomes was observed as measured by lung function as well as health-related quality of life questionnaires. The post bronchodilator \% predicted $\mathrm{FEV}_{1}$ was similar at baseline and after treatment in the SFC and FP treatment group and a decrease of $6 \%$ from baseline was seen in the placebo group. Clinically, all treatments were well tolerated and only one patient (treated with FP) experienced a drug-related adverse event (candidiasis). Three patients experienced post-bronchoscopy pneumonitis that was thought to be associated with the BAL procedure.

\section{DISCUSSION}

Our study has shown that the combination of salmeterol and FP reduces aspects of airway inflammation in patients with COPD and that these effects are not observed with FP alone. We have demonstrated a reduction in CD8+ $\mathrm{T}$ lymphocytes and CD68+ macrophages following 12 weeks of treatment with combination therapy. Both these cell types appear to be important in the pathogenesis of COPD. ${ }^{4-6}$ Treatment with FP did not have these effects, giving only small non-significant decreases in the number of CD8+ cells compared with placebo and having no effects on CD68+ macrophages. Combination treatment reduced neutrophil number counts compared with FP treatment but not compared with placebo. We did not demonstrate an effect of either active treatment on eosinophils in bronchial biopsies. The numbers of eosinophils observed in the airways of these patients with stable COPD was low and our data do not provide support for an important role for these cells in stable COPD.

COPD is recognised as an inflammatory disease ${ }^{21}$ so treatments that reduce inflammatory cells in patients with COPD may be of importance in therapeutic management. CD8+ cells in the airways and lung parenchyma have been shown to correlate significantly with the degree of airflow limitation, which suggests that CD8+ cells may be related to the progression of the disease. ${ }^{4}$

Cytotoxic CD8+ cells have the potential to release mediators such as tumour necrosis factor $\alpha$, interferon $\gamma$, perforins and granzymes, leading to lung destruction. Increased macrophage 
Table 2 Biopsy cell counts (cells $/ \mathrm{mm}^{2}$ ) according to treatment allocation

\begin{tabular}{|c|c|c|c|}
\hline & $\begin{array}{l}\text { SFC } \\
(n=19)\end{array}$ & $\begin{array}{l}\text { FP } \\
(n=17)\end{array}$ & $\begin{array}{l}\text { Placebo } \\
(n=15)\end{array}$ \\
\hline $\begin{array}{l}\text { CD8+ T lymphocytes } \\
\text { Baseline mean } \\
\text { Post-treatment mean } \\
\text { Mean change from baseline } \\
\text { Median change from baseline } \\
\text { p Value for mean change from baseline }\end{array}$ & $\begin{array}{l}191(79) \\
107(31) \\
-84(67) \\
-75(-110 \text { to }-34) \\
<0.001\end{array}$ & $\begin{array}{l}195(69) \\
164(67) \\
-31(47) \\
-24(-51 \text { to }-15) \\
0.20\end{array}$ & $\begin{array}{l}187(43) \\
201(48) \\
14(41) \\
11(-4 \text { to } 41.50) \\
0.42\end{array}$ \\
\hline $\begin{array}{l}\text { CD68+ macrophages } \\
\text { Baseline mean } \\
\text { Post-treatment mean } \\
\text { Mean change from baseline } \\
\text { Median change from baseline } \\
\text { p Value for mean change from baseline }\end{array}$ & $\begin{array}{l}102(37) \\
74(24) \\
-29(22) \\
-30(-41 \text { to }-10) \\
0.008\end{array}$ & $\begin{array}{l}122(49) \\
122(49) \\
0(33) \\
-2(-15 \text { to } 30) \\
0.98\end{array}$ & $\begin{array}{l}135(53) \\
136(40) \\
2(49) \\
20(-38 \text { to } 34) \\
0.88\end{array}$ \\
\hline $\begin{array}{l}\text { Neutrophils } \\
\text { Baseline mean } \\
\text { Post-treatment mean } \\
\text { Mean change from baseline } \\
\text { Median change from baseline } \\
\text { p Value for mean change from baseline }\end{array}$ & $\begin{array}{l}50(19) \\
41(19) \\
-9(18) \\
-11(-19 \text { to } 0.5) \\
0.16\end{array}$ & $\begin{array}{l}53(20) \\
67(24) \\
14(12) \\
18(6 \text { to } 21) \\
0.07\end{array}$ & $\begin{array}{l}41(26) \\
36(21) \\
-4(15) \\
-4(-11 \text { to } 7.5) \\
0.62\end{array}$ \\
\hline $\begin{array}{l}\text { Eosinophils } \\
\text { Baseline mean } \\
\text { Post-treatment mean } \\
\text { Mean change from baseline } \\
\text { Median change from baseline } \\
\text { p Value for mean change from baseline }\end{array}$ & $\begin{array}{l}5(5) \\
5(4) \\
-0.4(5) \\
0(-3 \text { to } 3) \\
0.80\end{array}$ & $\begin{array}{l}9(7) \\
8(7) \\
-1(6) \\
-1(-2 \text { to } 3) \\
0.61\end{array}$ & $\begin{array}{l}7(4) \\
9(5) \\
3(7) \\
1(0.5 \text { to } 7) \\
0.09\end{array}$ \\
\hline
\end{tabular}

SFC, salmeterol xinafoate/fluticasone propionate; FP, fluticasone propionate.

Data expressed as mean (SD) or median (interquartile ranges).

numbers in the airways are associated with parenchymal destruction and COPD severity. ${ }^{27}$ CD68 macrophages mainly release tumour necrosis factor $\alpha$, a proinflammatory cytokine which is involved in systemic inflammation as well as tissue hypoxia and muscle wasting seen in COPD. ${ }^{30}$

Reduction of CD8+ cells by SFC in the airways of patients with COPD has also been demonstrated in a recent study by Barnes and colleagues. ${ }^{20}$ That study, however, did not include an inhaled corticosteroid treatment group so our results, in addition to confirming the effects of combination treatment on CD8+ cells, also provide evidence that, in large part, the effect is not related to the action of inhaled corticosteroids alone. In contrast to these investigators, we also observed an effect of combination treatment on CD68+ macrophages, providing further evidence for enhanced anti-inflammatory effects of combination treatment. Effects on macrophages have not been observed with inhaled corticosteroids alone. ${ }^{16}$ Our results demonstrating an increased number of neutrophils following FP treatment were not surprising, yet they further support the possibility that corticosteroids inhibit neutrophilic apoptosis, thus prolonging their survival, as previously shown. ${ }^{31}$ The failure to show a significant change in neutrophil counts following combination treatment, however, may have resulted from the ability of salmeterol to reduce the number of neutrophils by promoting their apoptosis and reducing levels of interleukin-8, a key neutrophil chemoattractant. Although these effects have been well established in vitro and in asthma, $^{32}$ only a salmeterol treatment arm in this study design could confirm this possibility in COPD.

One limitation of the study is that we cannot extrapolate that the inflammatory changes are responsible for the improvement in clinical outcomes shown in previous studies. For example, in the study by Barnes et al, ${ }^{20}$ the anti-inflammatory effect of SFC was accompanied by significant improvements in lung function. Our study was not powered to detect an effect on clinical outcomes and, furthermore, the study was of relatively short duration which may have limited the possibility of showing any benefit on quality of life. This study was also not designed to assess the effects on COPD exacerbations; previous studies have shown that a reduction in exacerbations has been observed with combination therapy. ${ }^{17}$ The biopsy specimens in this study were taken from the proximal rather than the distal airways, which is a clear limitation as the proximal airways may not closely reflect all the pathological changes present in the peripheral airways and lung parenchyma, which are the sites generally responsible for airflow limitation in COPD. ${ }^{33}$ However, increases in CD8+ cells have been observed in both the proximal and distal airways where a relationship between their numbers and reduced lung function has been shown. ${ }^{34}{ }^{35}$ As such, the site of the biopsy is possibly the reason for the discrepancy in inflammatory and clinical responses.

Subjects were allowed to use short-acting $\beta_{2}$ agonists both during the run-in period and during the study. Although one of the measures of interest was the interaction between inhaled corticosteroids and $\beta_{2}$ agonists, this is unlikely to have biased the results. Randomisation will tend to make study groups comparable and patients were kept blind to the assigned treatment. There is increasing evidence to suggest a synergistic and/or additive effect of long-acting $\beta_{2}$ agonists and inhaled corticosteroids on airway inflammation. ${ }^{36-39}$ Although the mechanisms for this observation are not entirely clear, in vitro studies suggest that corticosteroids may regulate $\beta_{2}$ receptor function by increasing expression of the receptor and by restoring $G$ protein $/ \beta_{2}$ receptor coupling and inhibiting $\beta_{2}$ receptor downregulation. By modulating glucocorticoid receptor phosphorylation, long-acting $\beta_{2}$ agonists prime the glucocorticoid receptor and affect its nuclear localisation. This interactive mechanism presumably leads to additive and/or synergistic effects of combination therapy on airway inflammation. ${ }^{35}$ Long-acting $\beta_{2}$ agonists may also have non-bronchodilator effects which are anti-inflammatory. ${ }^{40}$ They have been shown to inhibit mediator release from macrophages ${ }^{41}$ and, in patients with asthma, to reduce the number of neutrophils in bronchial biopsies. ${ }^{32}$ The design of our study does not allow us 
to define the effects of treatment with salmeterol alone in patients with COPD.

In summary, this study provides evidence of anti-inflammatory effects in patients with COPD for the combination of an inhaled corticosteroid with a long-acting $\beta_{2}$ agonist that are not observed with inhaled corticosteroid alone. The enhanced effects of combination therapy on key inflammatory cells may explain the clinical efficacy that has been shown in previous trials of COPD. Combination therapy reduced CD8+ cytotoxic T lymphocytes and CD68+ macrophages, cells that have been shown to be correlated with COPD disease severity and recognised to be important in the pathogenesis of COPD. However, a long-term study will be needed to determine whether combination therapy can modify the progressive nature of this disorder.

\section{ACKNOWLEDGEMENTS}

The authors acknowledge the support of Marthe Bélanger RN, Hôpital Laval, Institut Universitaire de Cardiologie et de Pneumologie de l'Université Laval; and Leo Cicora RT and Elizabeth Sukhdeo RT, Montreal Chest Institute, McGill University Health Centre.

\section{Authors' affiliations}

Jean Bourbeau, Pota Christodoulopoulos, Ronald Olivenstein, Respiratory Epidemiology and Clinical Research Unit, Montreal Chest Institute, McGill University Health Centre, Montréal, Quebec, Canada

Francois Maltais, Centre de recherche, Hôpital Laval, Institut Universitaire de cardiologie et de pneumologie, Université Laval, Québec, Canada Yasuhiro Yamauchi, Qutayba Hamid, Meakins Christie Laboratories, McGill University, Montréal, Quebec, Canada

This study was funded by an unrestricted research grant from GlaxoSmithKline.

Competing interests: None.

\section{REFERENCES}

1 Jeffrey PK. Differences and similarities between chronic obstructive pulmonary disease and asthma. Clin Exp Allergy 1999;29:14-26.

2 Finkelstein R, Fraser RS, Ghezzo $\mathrm{H}$, et al. Alveolar inflammation and its relation to emphysema in smokers. Am J Respir Crit Care Med 1995;152:1666-72.

3 O'Shaughnessy T, Ansari TW, Barnes NC, et al. Inflammation in bronchial biopsies of subjects with chronic bronchitis: inverse relationship of CD8+ T

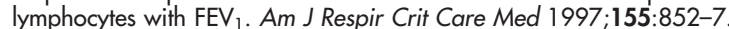

4 Saetta M, Baraldo S, Corbino L, et al. CD8+ve cells in the lungs of smokers with chronic obstructive pulmonary disease. Am J Respir Crit Care Med 1999;160:711-7.

5 Di Stefano A, Capelli A, Lusuardi M, et al. Severity of airflow limitation is associated with severity of airway inflammation in smokers. Am J Respir Crit Care Med 1998;158:1277-85.

6 Shapiro SD. The macrophage in chronic obstructive pulmonary disease. Am J Respir Crit Care Med 1999;160:S29-32.

7 Rutgers SR, Postma DS, ten Hacken NHT, et al. Ongoing airway inflammation in patients with COPD who do not currently smoke. Thorax 2000:55:12-8.

8 Finlay GA, O'Driscoll LR, Russell KJ, et al. Matrix metalloproteinase expression and production by alveolar macrophages in emphysema. Am J Respir Crit Care Med 1997; 156:240-7.

9 Di Stefano A, Furato G, Maestrelli P, et al. Airflow limitation in chronic bronchitis is associated with T-lymphocyte and macrophage infiltration of the bronchial mucosa. Am J Respir Crit Care Med 1996;153:629-32.

10 Keatings VM, Barnes PJ. Granulocyte activation markers in induced sputum: comparison between chronic obstructive pulmonary disease, asthma and normal subjects. Am J Respir Crit Care Med 1997;155:449-53.

11 Stockley RA. Neutrophils and the pathogenesis of COPD. Chest 2002;121:151-5s.

12 Stanescu D, Sanna A, Veriter C, et al. Airways obstruction, chronic expectoration, and rapid decline of FEV 1 in smokers are associated with increased levels of sputum neutrophils. Thorax 1996:51:267-71.

13 Fabbri LM, Romaggnoli M, Corbetta L, et al. Differences in airway inflammation in patients with fixed airflow obstruction due to asthma or chronic obstructive pulmonary disease. Am J Respir Crit Care Med 2003;167:418-24.
14 Alsaeedi A, Sin DD, McAlister FA. The effects of inhaled corticosteroids in chronic obstructive pulmonary disease: a systematic review of randomized placebo-controlled trials. Am J Med 2002;113:59-65.

15 Keatings VS, Jatakanon A, Worsdell YM, et al. Effects of inhaled and oral glucocorticoids on inflammatory indices in asthma and COPD. Am J Respir Crit Care Med 1997; 155:542-8.

16 Hattotuwa KL, Gizycki MJ, Ansari TW, et al. The effects of inhaled fluticasone on airway inflammation in chronic obstructive pulmonary disease: a double-blind placebo-controlled biopsy study. Am J Respir Crit Care Med 2002;165:1592-6.

17 Calverley P, Pauwels R, Vestbo J, et al. Combining salmeterol and fluticasone in the treatment of chronic obstructive pulmonary disease. Lancet 2003;361:449-56.

18 Mahler DA, Wire P, Horstman D, et al. Effectiveness of fluticasone propionate and salmeterol combination delivered via the Diskus device in the treatment of chronic obstructive pulmonary disease. Am J Respir Crit Care Med 2002; 166:1084-91.

19 Szafranski W, Cukier A, Ramirez R, et al. Efficacy and safety of budesonide/ formoterol in the management of chronic obstructive pulmonary disease. Eur Respir J 2003;21:74-81.

20 Barnes NC, Qiu Y-S, Pavord ID, et al. Anti-inflammatory effects of salmeterol/ fluticasone propionate in chronic obstructive lung disease. Am J Respir Crit Care Med 2006;173:736-43.

21 Global Initiative for Chronic Obstructive Lung Disease. Global strategy for the diagnosis, management, and prevention of chronic obstructive lung disease, $\mathrm{NHLBI/WHO}$ Workshop Report. Bethesda: National Heart Lung and Blood Institute, 2001; update of the Management sections, www.goldcopd.com (accessed 29 March 2006).

22 Guyatt GH, Berman LB, Townsend M, et al. A measure of quality of life for clinical trials in chronic lung disease. Thorax 1987;42:773-8.

23 American Thoracic Society. Recommended respiratory disease questionnaire for use with adults and children in epidemiological research. Am Rev Respir Dis 1978;118:1-53.

24 American Thoracic Society. Workshop summary and guidelines: investigative use of bronchoscopy, lavage and bronchial biopsies in asthma and other airway diseases. J Allergy Clin Immunol 1991;88:808-14.

25 Ying S, Durham SR, Barkans J, et al. T cells are the principal source of interleukin5 mRNA in allergen-induced rhinitis. Am J Respir Cell Mol Biol 1993:9:356-60.

26 Jeffrey PK, Holgate S, Wenzel SE. Methods for the assessment of endobronchial biopsies in clinical research. Am J Respir Crit Care Med 2003;168:S1-17.

27 Azzawi M, Bradley B, Jeffery PK, et al. Identification of activated T lymphocytes and eosinophils in bronchial biopsies in stable atopic asthma. Am Rev Respir Dis 1990;142:1407-13.

28 Moqbel R, Barkans J, Bradley BL, et al. Application of monoclonal antibodies against major basic protein (BMK-13) and eosinophil cationic protein (EG1 and EG2) for quantifying eosinophils in bronchial biopsies from atopic asthma. Clin Exp Allergy 1992;22:265-73.

29 Johnston N, Knight J, Dettmar P, et al. Pepsin and carbonic anhydrase isoenzyme III as diagnostic markers for laryngopharyngeal reflux disease. Laryngoscope 2004;114:2129-34.

30 Pitsiou G, Kyriazis G, Hatzizisi O, et al. Tumour-necrosis factor-alpha serum levels, weight loss and tissue oxygenation in chronic obstructive pulmonary disease. Respir Med 2002;96:594-8.

31 Haslett C. Granulocyte apoptosis and its role in the resolution and control of lung inflammation. Am J Respir Crit Care Med 1999;160:S5-11.

32 Jeffery PK, Venge P, Gizycki MJ, et al. Effects of salmeterol on mucosal inflammation in asthma: a placebo-controlled study. Eur Respir J 2002;20:1378-85.

33 Hogg JC, Chu F, Utokaparch S, et al. The nature of small-airway obstruction in chronic obstructive pulmonary disease. N Engl J Med 2004;350:2645-53.

34 Saetta M, Di Stefano A, Turato G, et al. CD8+ T-lymphocytes in peripheral airways of smokers with chronic obstructive pulmonary disease. Am J Respir Crit Care Med 1998; 157:822-6.

35 Lams BEA, Sousa AR, Rees PJ, et al. Subepthelial immunopathology of large airways in smokers with and without chronic obstructive pulmonary disease. Eur Respir J 2000;15:512-6.

36 Johnson $M$. Interactions between corticosteroids and $\beta_{2}$ agonists in asthma and chronic obstructive pulmonary disease. Proc Am Thorac Soc 2004;1:200-6.

37 Pace E, Gagliardo R, Melis M, et al. Synergistic effects of fluticasone propionate and salmeterol on in vitro T-cell activation and aopoptosis in asthma. J Allergy Clin Immunol 2004;114:1216-23.

38 Wallin A, Sue-Chu M, Bjermer $L$, et al. Effect of inhaled fluticasone with and without salmeterol on airway inflammation in asthma. J Allergy Clin Immunol 2003; 1 12:72-8.

39 Adcock IM, Maneechotesuwan K, Usmani O. Molecular interactions between glucocorticoids and long-acting $\beta_{2}$ agonists. J Allergy Clin Immunol 2002;110:S261-8.

40 Johnson JM, Rennard S. Alternative mechanisms for long-acting $\beta_{2}$-adrenergic agonists in COPD. Chest $2001 ; 120: 258-70$.

41 Baker A, Palmer J, Johnson M, et al. Inhibitory activities of salmeterol on human airway macrophages and blood monocytes. Eur J Pharmacol 1994;2764:301-6. 